\title{
WAVE OVERWASH OF VEGETATED DUNES
}

\author{
Christine Gralher ${ }^{1}$, Nobuhisa Kobayashi ${ }^{1}$ and Kideok Do ${ }^{1}$,
}

Sand dunes play a significant role during coastal storms by absorbing the impacts of storm surge and high waves. Therefore, rapid profile changes and destruction of sand dunes, which may be caused by wave-induced overwash, lead to an increased flood risk landward of dunes. The effects of vegetation on dune erosion and overwash during storm events, however, have never been studied. This study is based on a laboratory experiment investigating the effects of woody plants on dune erosion and overwash of high and low dunes. During the five tests conducted foredune scarping was observed for the three high dune tests but did not occur for the two low dune tests. A narrow vegetation placed on the steep backdune of the high dune did not reduce wave overtopping and sand overwash. However, the wide vegetation figuration, which covered the backdune and foredune, reduced foredune scarping, prevented wave overtopping initially and reduced sand overwash after the initiation of wave overtopping for the high dune. It also slowed down the erosion process of the low dune significantly by retarding wave uprush and reducing wave overtopping and overwash.

Keywords: vegetation; wave overtopping; dune; erosion; overwash; sediment transport

\section{INTRODUCTION}

An accelerated population growth in coastal areas is noticed worldwide. The United Nations Atlas of the Oceans stresses that $44 \%$ of the world's population live less than $150 \mathrm{~km}$ away from the coast. According to Crowell et al. (2010), 8,651,000 people alone in the U.S., which is slightly more than 3\% of the U.S. population, live in areas subjected to the $1 \%$ annual chance (100 year) coastal flood. The vulnerability of coastal areas and the sea level rise emphasize the importance of coastline storm protection. Gutierrez et al. (2007) point out that shoreline erosion and dune overwash will increase with mean sea level rise. In many coastal areas, dunes (natural and artificial) play an important role in coastal protection. Tropical and extra-tropical storms, however, can lead to major coastal overwash events that may cause dune breaching, inundation, and serious damage to the coastal infrastructure.

In addition to the application of vegetation to stabilize dunes against aeolian sand transport, wave attenuation by vegetation has been investigated in relation to the prediction of wind waves (and also tsunamis) propagating across inundated, vegetated areas. However, the effects of vegetation on dune erosion and overwash during storm events have never been studied.

This investigation examines a possible non-intrusive form of shore protection: Vegetation which supports shoreline protection by dampening incoming waves and depositing sediment in vegetated regions. Rosati and Stone (2009) suggested active planting of vegetation as one possible countermeasure to reduce the severity of dune overwash and flooding.

This study is based on a laboratory experiment conducted in a wave flume to quantify the vegetation effects on wave overwash and dune profile evolution. It focuses on woody, rigid plants that may reduce overtopping flow more than grass. Cylindrical wooden dowels were used in this experiment to represent the chosen vegetation characteristics. In addition to two different dune geometries (high and low dunes), narrow and wide vegetation figurations were examined and compared to dunes under bare conditions. Besides hydrodynamic measurements the study focused on the determination of high resolution profile measurements and measuring wave overtopping and sand overwash. The experiment showed that the wide vegetation reinforced the dune and hence, slowed down the erosion process noticeably in contrary to the narrow vegetation which had only little effect on the process. In the following section a brief overview of the experimental setup and measurements is given before illustrating the results of this study.

\section{EXPERIMENT}

The experiment was conducted in a $23 \mathrm{~m}$ long and $1.15 \mathrm{~m}$ wide section of the University of Delaware's Sand Tank. Figure 1 depicts a schematic sketch of the experimental setup. A piston-type wave maker generated sets of 400-s bursts of irregular waves in a water depth of $1 \mathrm{~m}$. On top of the plywood bottom with a slope of 1:30 the beach and dune profile consisted of well-sorted fine sand with a median diameter of $0.18 \mathrm{~mm}$. The sand's characteristics including the specific gravity, porosity and fall velocity were $2.6,0.4$ and $2.0 \mathrm{~cm} / \mathrm{s}$. Free surface elevation and fluid velocity were recorded with a sampling frequency of $20 \mathrm{~Hz}$. Wave gauges (WG) were installed along the centerline of the flume at eight locations to measure the wave transformation from offshore to the dune profile. WG1 to WG8

\footnotetext{
${ }^{1}$ Center for Applied Coastal Research, Department of Civil \& Environmental Engineering, University of Delaware, 259 Academy St, Newark, DE, 19716, U.S.A, E-mail: gralher@udel.edu.
} 
were located at the onshore coordinates $\mathrm{x}=0.0,0.25,0.95,8.3,12.9,15.5,17.1$ and $18.6 \mathrm{~m}$. Three acoustic Doppler velocimeters were employed to measure the wave-induced and mean (undertow) velocities in the surf zone at $\mathrm{x}=12.9,15.5$ and $17.1 \mathrm{~m}$.

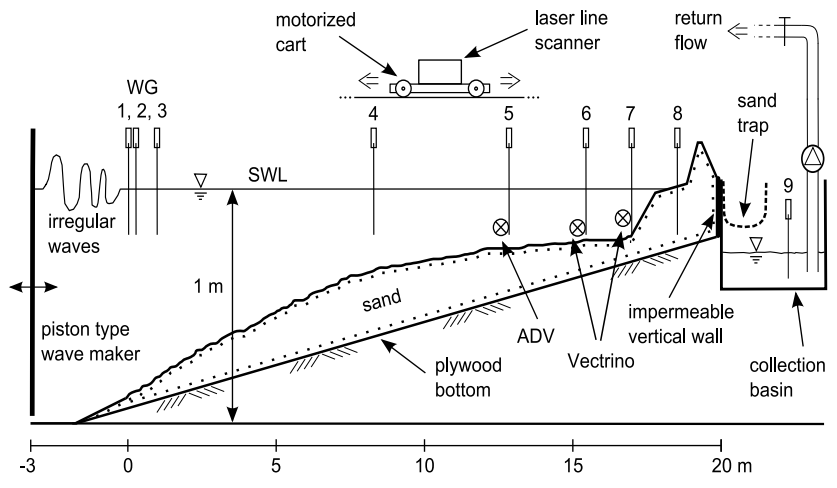

Figure 1. Schematic view of the experimental setup.

In addition to hydrodynamic measurements, information on wave overtopping and sand overwash was necessary to investigate the effects of vegetation on dune erosion. Therefore, an overwash collection basin including a sediment trap was installed landward of the dune to measure the water and sand transported over the impermeable vertical wall (shown in Figure 1) during each 400-s burst. The crest of the wall, which separated the beach profile from the overwash collection unit at $\mathrm{x}=19.9 \mathrm{~m}$, was $6 \mathrm{~cm}$ above the still water level (SWL). The sediment trap consisting of a polyester fabric mesh retained particles with diameters exceeding $0.074 \mathrm{~mm}$. A recirculation system including an inline flow meter pumped the collected water back into the flume to ensure a constant water level. High resolution profile measurements were an important part of this study. The water level was lowered after the wave run and subsequently the subaerial portion of the sand bed was recorded by a laser line scanner system. An array of three ultrasonic transducers was used to measure the offshore portion of the profile in the remaining submerged part of the flume.

Rigid woody plants, which may reduce overtopping flow more than grass, are represented in this study by cylindrical wooden dowels. Figure 2 illustrates the selected dowels with a diameter and length of $0.9 \mathrm{~cm}$ and $30 \mathrm{~cm}$, respectively. The burial depth of $l_{b}=20 \mathrm{~cm}$ and the emerged height of $1_{\mathrm{e}}=10 \mathrm{~cm}$ were chosen in this experiment. It has to be noted that uprooting was not considered in this experiment. The profile changed rapidly in the region where the dowels were placed; therefore the burial depth was adjusted to $20 \mathrm{~cm}$ after each run. The uniform spacing among the dowels was $4 \mathrm{~cm}$.
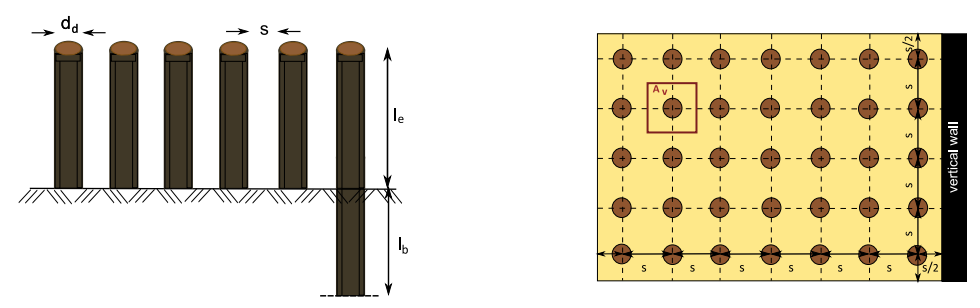

Figure 2. Parameters of the chosen dowels modeling vegetation (left) and schematic top view of the dowel field showing a uniform spacing in all directions (right).

The five tests conducted are listed in sequence in Table 1 where each test comprised a number of the same 400-s bursts of irregular waves. A high $(\mathrm{H})$ and a low (L) dune were tested in this study. In addition to the two dune geometries, narrow and wide vegetation configurations were investigated. While the narrow vegetation zone was limited to the backdune, the wide vegetation covered the backdune and foredune. The high bare (HB) and the high narrowly vegetated (HN) dune were both eroded to the level of the vertical wall crest after 6 runs. The high and widely vegetated (HW) dune however, was more resilient and was terminated due to alongshore variability after 28 runs. The final 
profile was smoothed and the created uniform alongshore profile was used as the initial profile for the low bare dune (LB) test. The dune was eroded to the level of the vertical wall after 3 runs. The wide vegetation reinforced the initial low dune profile and the test (LW) was continued for 20 runs to examine the temporal variations of the wave overtopping and overwash rates after the vertical wall was exposed to wave action. In the following sections the integer affixed to the test name indicates the run number. Pictures of the vegetation fields covering the initial profiles of the HN, HW, and LW tests are shown in Figure 3.
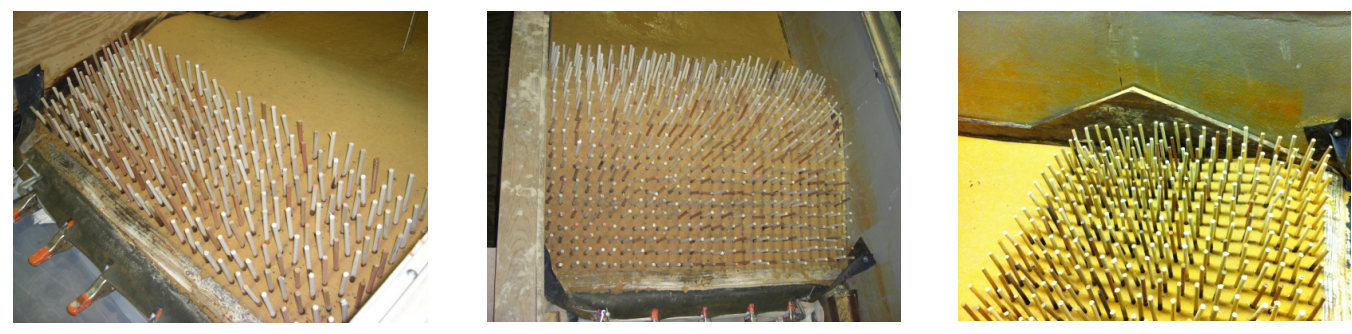

Figure 3. Vegetation configurations for the HN (left), HW (middle), and LW (right) test under initial conditions. The HW and LW tests show the same setup of the vegetation field.

\begin{tabular}{|c|c|c|c|c|}
\hline \multicolumn{6}{|c|}{ Table 1. Test overview. } \\
\hline Test & Dune & Vegetation & $\begin{array}{c}\text { Number of } \\
\text { runs }\end{array}$ & $\begin{array}{c}\text { Total duration } \\
(\mathrm{s})\end{array}$ \\
\hline HB & High & Bare & 6 & 2,400 \\
HN & High & Narrow & 6 & 2,400 \\
HW & High & Wide & 28 & 11,200 \\
LB & Low & Bare & 3 & 1,200 \\
LW & Low & Wide & 20 & 8,000 \\
\hline
\end{tabular}

\section{DATA ANALYSIS}

\section{Hydrodynamics}

The water free surface elevation $(\eta)$ was recorded during each wave run where the first $20 \mathrm{~s}$ of each 400-s time series are not included in the statistical analysis to avoid any influences by the transitional phase. The wave gauges installed offshore (WG1-WG3) were used to separate incident and reflected waves at WG1. The average spectral significant wave height and peak period throughout the experiments were approximately $19 \mathrm{~cm}$ and $2.7 \mathrm{~s}$, respectively. The berm profile at the location of WG8 changed rapidly; therefore the instrument was not always submerged throughout the entire run. For the calculation of the statistical values of $\eta$, only the data points within the wet duration are included in the analysis. A detailed description of the separation procedure of wet and dry data points is given by Figlus et al. (2011). The likelihood of a wave gauge to be submerged in water at any given time during the respective run is described by the wet probability $\left(\mathrm{P}_{\mathrm{w}}\right)$ and calculated by dividing the points within the wet duration by the total number of data points. The results of the cross-shore and temporal variations of the statistical values for the high and the low dune test series are summarized in Figure 4 . The upper panel depicts $\bar{\eta}$ with its standard deviation $\sigma_{\eta}$ shown in the middle panel. $\mathrm{P}_{\mathrm{w}}$ for all eight wave gauges is included in the bottom panel of the high dune test series. All values are plotted as a function of $\mathrm{x}(\mathrm{m})$ where each circle represents the specific run and cross-shore location. The temporal variation is shown by the color scheme ranging from red for the first to the respective final run plotted in blue. A setdown $(\bar{\eta}<0)$ for WG1-WG4 and a setup $(\bar{\eta}>0)$ for WG5-WG8 was observed for both test series. Except for the buried wave gauge (WG8), which is affected by rapid bottom elevation change, $\bar{\eta}$ and $\sigma_{\eta}$ show only minor variations over time. Sand eroded from the dune was deposited in the berm region at the beginning of each test before the continuous erosion started. That is why the value of $\bar{\eta}$ shows an increase before it continuously decreases due to the eroding bottom elevation. The standard deviation which can be expressed by the spectral significant wave height $\left(H_{m o}=4 \sigma_{\eta}\right)$ decreases in the surf and swash zone. WG8 was not submerged during the first five runs of HB and HN. Since the wide vegetation slowed down the erosion process noticeably, the wave gauge showed dry durations 
until the end of HW7. The wet probability became 1.0 after WG8 was seaward of the still water shoreline due to erosion. All other wave gauges were continuously submerged throughout the high dune test series. For the low dune test series WG8 was continuously submerged throughout the entire test.
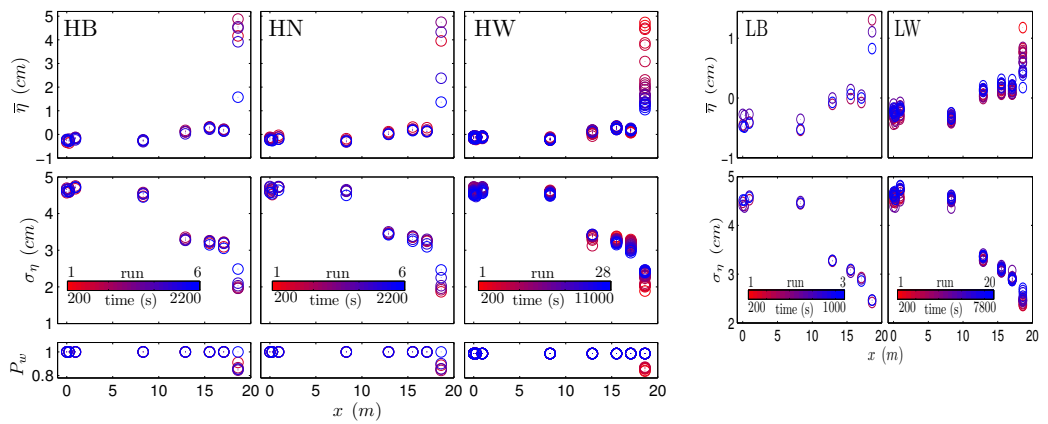

Figure 4. Cross-shore variations of $\bar{\eta}$ (top) and $\sigma_{\eta}$ (middle) for the high (left) and low (right) dune test series. The bottom panel of the high dune test series shows the wet probability $P_{w}$.

Fluid velocity was recorded at WG5, WG6 and WG7. The sampling volume of each velocimeter was placed at $2 / 3$ of the local water depth below SWL above the local bottom. This study focused on the mean cross-shore velocity $(\bar{u})$ and its standard deviation $\left(\sigma_{u}\right)$ since the alongshore and vertical velocities were comparably small. Figure 5 shows the average values of $\bar{u}$ and $\sigma_{u}$ for all runs of the high (left) and low (right) dune test series. The data is represented in the same way as the wave gauge results which is explained above. Both test series show similar results for the analysis of the velocity due to negligible differences in the offshore profile and generating the same set of waves for each run. The value of $\bar{u}$ was negative throughout the entire experiment, which indicates the existence of an offshore undertow current. The current decreases between $x=12.9 \mathrm{~m}$ and $\mathrm{x}=15.5 \mathrm{~m}$ before it increases at $x=17.1 \mathrm{~m}$ where some broken waves in the inner surf zone broke again on the steeper bottom slope. The respective standard deviation shows only minor variations in the inner surf zone between $x=12.9$ $17.1 \mathrm{~m}$ during each test. However, it increased at $\mathrm{x}=17.1 \mathrm{~m}$ probably due to increased wave breaking on the steeper bottom slope.
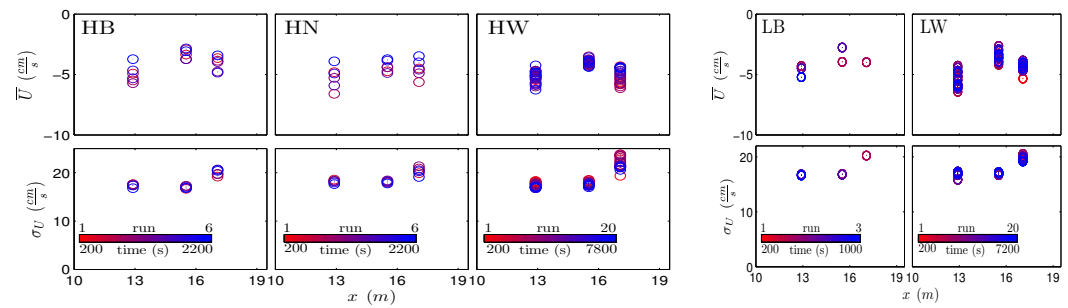

Figure 5. Cross-shore variations of $\overline{\mathbf{u}}$ (top) and $\sigma_{u}$ (bottom) for the high (left) and low (right) dune test series.

\section{Profile Evolution}

The main focus of this study is the comparison of profile evolution of bare and vegetated dunes in presence of wave overtopping and overwash to gain a better understanding of vegetation effects on dune and beach profile evolution. The bottom elevation measured by the laser scanner system was averaged alongshore to obtain the cross-shore profile evolution over time for all tests. Readings were taken at an interval of $2 \mathrm{~cm}$. However, the profile within the vegetation field was measured every $1 \mathrm{~cm}$ to gain a sufficient number of profile scans since some scans captured mostly the vegetation and not the actual sand bottom profile. The most prominent profile changes occurred in the zone between $x=16$ $19.90 \mathrm{~m}$ which are illustrated in Figure 6 for the high (left) and low (right) dune test series. Profile elevation was chosen to be positive in upward direction with $\mathrm{z}=0$ at SWL. The temporal change is 
represented by the color scheme ranging from red to blue. Furthermore, each profile is identified by its run number where run number 0 describes the initial profile. The zone of the vegetation is indicated in the plots.

Figure 6 depicts the profile evolution of the HB (top), HN (middle), and HW (bottom) test on the left. HB and HN show a similar profile evolution. Rapid changes in profile elevation were observed during the first run due to the rather artificial geometry of the foredune. The eroded sediment was mainly transported offshore. Due to the adjustment of the initial profile to the wave conditions, profile changes slowed down. However, the dune crest was lowered continuously and the scarping and slumping processes (pictures in Figure 7) at the dune face moved the dune crest further onshore. The increasing wave overtopping lead to an increase in backdune erosion. At the end of the tests the final dune profile showed a horizontal platform in front of the vertical wall at the level of the wall's crest. The wide vegetation, however, protected the fordune against direct wave attack and scarping. Hence, the erosion process was slowed down noticeably. Overtopping did not occur until after run HW20 $(8,000 \mathrm{~s})$ and remained small until the end of the test. The HW test was terminated when the profile differences in alongshore direction were not negligible.

Scarping and slumping processes did not occur on the foredune during the low dune test series as shown on the right in Figure 6 which illustrates the profile evolution of the LB (top) and LW (bottom) test. After only 1,200 s the low bare dune profile was eroded to the level of the vertical wall's crest. As observed for the high dune test series, the process was slower for the wide vegetation covering the backdune and foredune landward of SWL. With the progression of the foredune erosion, the still water shoreline moved landward and the vegetation zone became more exposed to broken waves in the inner surf zone. The picture on the right in Figure 7 shows the small hump that was formed in front of the first row of the vegetation at the seaward edge. The continuous scour in front of the vertical wall caused the tip of the vertical wall to be exposed to direct wave action towards the end of the LW test. The sand reinforcement effect by the buried parts (idealized roots) of the dowels appeared to be negligible for the LW test with no scarping.
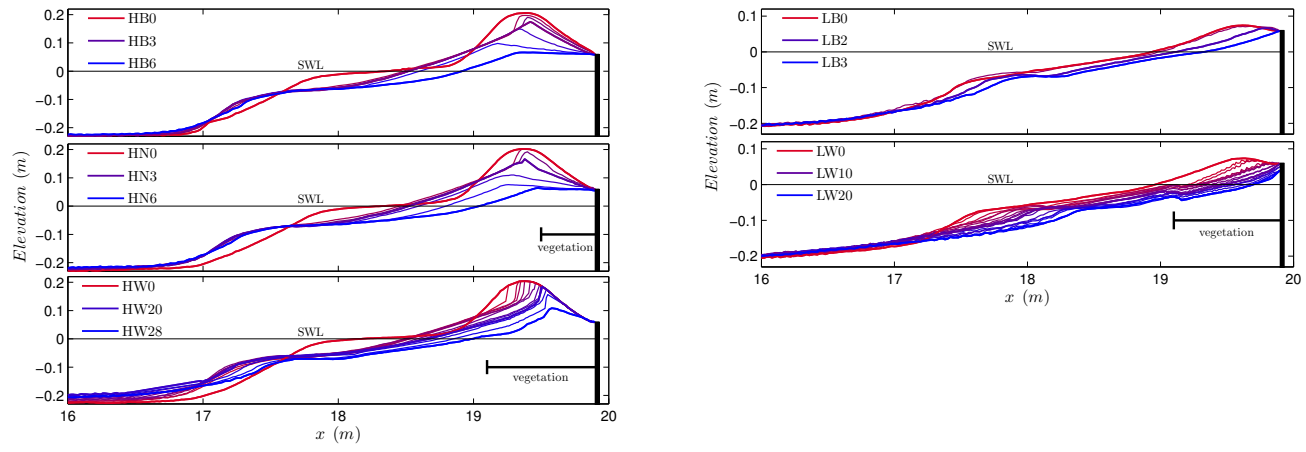

Figure 6. Dune profile evolution for the high (left) and low (right) dune test series.
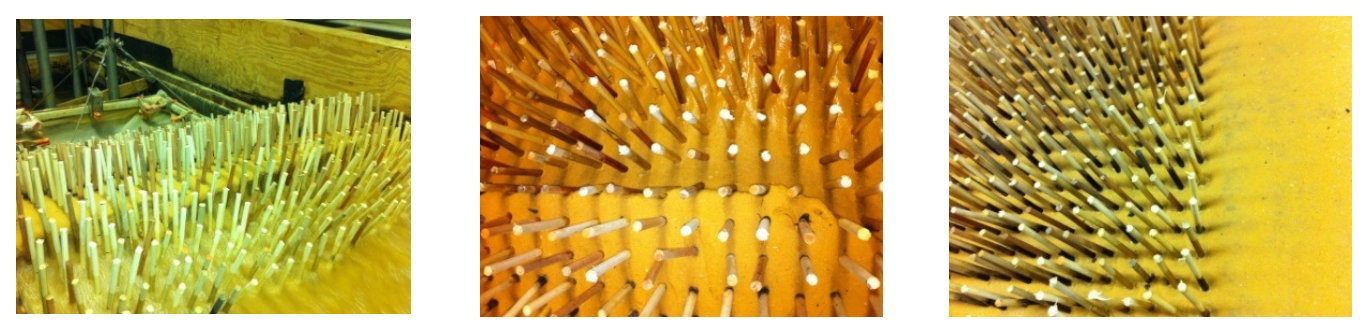

Figure 7. Photos taken during the HW (left and middle) and LW (right) tests illustrating scarping and slumping processes for the high dune test series and the hump formed during the low dune test with the wide vegetation. 


\section{Overwash and Overtopping}

After each run the wet sand was removed from the trap and its wet and dry mass was determined to calculate the total water and sand volume transported over the vertical wall within the respective 400s. The temporal variations of the measured transport rates and their ratio are shown in Figure 8 for the high (left) and low (right) dune test series. For both test series the water overtopping rate $\left(\mathrm{q}_{\mathrm{o}}\right)$, the sediment overwash rate $\left(\mathrm{q}_{\mathrm{bs}}\right)$ and the ratio of those two values are shown in the top, middle and bottom panel, respectively. The transport rates $\left(\mathrm{cm}^{2} / \mathrm{s}\right)$ represent averages over the respective run lasting $400 \mathrm{~s}$. Therefore, each data point is plotted at time $t$ corresponding to the middle of each run.

For the HB (red, circles) and HN (green, squares) tests $\mathrm{q}_{\mathrm{o}}$ started to increase rapidly with time after the third run $(\mathrm{t}=1,200 \mathrm{~s})$. The dune crest was lowered initially by the seaward sand transport and fordune scarping and subsequently by wave overtopping and overwash over the vertical wall. The similarity of the overtopping and overwash rates for the HB and HN tests clearly shows that the narrow vegetation on the steep backdune did not reduce backdune erosion caused by the overtopping flow. For the HW test however, wave overtopping did not occur until the end of HW20 (blue, diamonds) after $8,000 \mathrm{~s}$ of generated waves. Therefore, $\mathrm{q}_{\mathrm{bs}}$ and $\mathrm{q}_{\mathrm{o}}$ were zero for the duration from HW1 to HW20 and it remained small until the end of the test. After 8,000 s backdune erosion caused by overtopping started and slowly progressed. Therefore, the value of $\mathrm{q}_{\mathrm{o}}$ increased but remained relatively small until the end of the test which was terminated due to alongshore variability.

The results of the low dune test series confirm that the wide vegetation was effective in reducing $\mathrm{q}_{\mathrm{o}}$ and $\mathrm{q}_{\mathrm{bs}}$. During the LW test the wide vegetation retarded wave uprush on the upward slope in the swash and inner surf zone and reduced the wave overtopping rate and the sand overwash rate by a factor of above 3 and 2, respectively. The overtopping rate remained almost constant throughout the LW test. With the progression of erosion in front of the vertical the sand overwash rate decreased which may be explained by the reduced availability of sand in the overtopping flow. Even after its seaward segment was situated in the inner surf zone, the wide vegetation was effective in reducing $\mathrm{q}_{\mathrm{o}}$.

The ratio $\left(\mathrm{q}_{\mathrm{o}} / \mathrm{q}_{\mathrm{bs}}\right)$, which represents the volumetric sand concentration in the overtopping flow, was about 0.2 in all five tests at the beginning of wave overtopping and overwash. This may indicate that loose sand particles on the surface were transported. The ratio decreased with the increase of the wave overtopping rate. The ratio for the $\mathrm{HW}$ and LW tests decreased at a slower rate which suggests that vegetation may have generated additional turbulence and increased sand concentration.
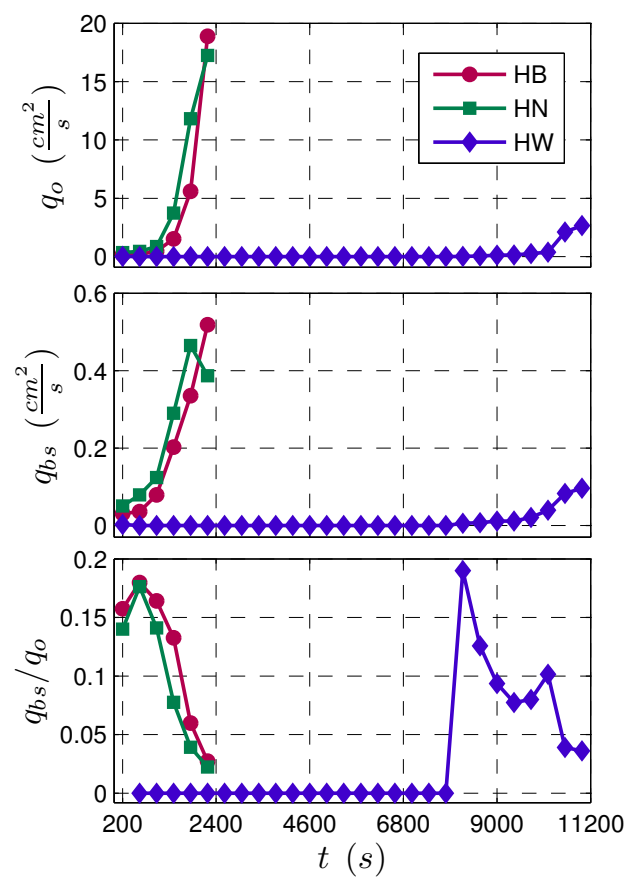
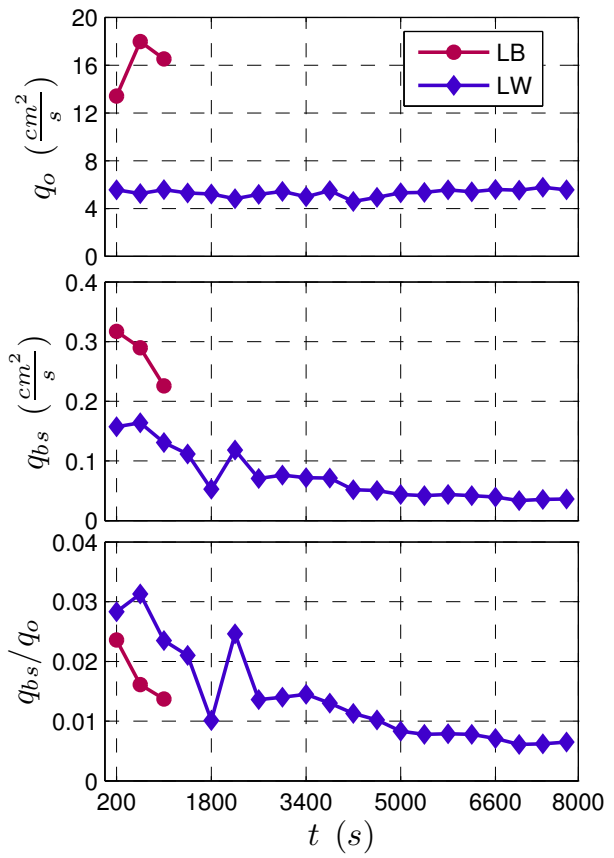

Figure 8. Temporal variations of wave overtopping rate $q_{0}$ (top), sand overwash rate $q_{b s}$ (middle) and ratio $q_{b s} / q_{o}$ (bottom) for the high (left) and low (right) dune test series. 


\section{CONCLUSION}

This study focused on the investigation of effects of woody plants on dune erosion and overwash. For this purpose a laboratory experiment with a total number of five tests was conducted. Two different dune geometries, high and low dunes, were tested under bare and vegetated conditions. The vegetation configurations included a narrow vegetated zone covering the backdune and a wide vegetation zone spanning the backdune and the foredune. Both configurations showed a uniform field of cylindrical wooden dowels with the same stem density. Eight capacitance wave gauges and three velocimeters recorded hydrodynamic data continuously throughout the entire duration of the experiment. High resolution bathymetry of the beach profile was provided by the laser line scanner system. The installation of the collection basin including the sediment trap, in which water and sediment transported over the low-crested vertical wall was collected, allowed for the examination of wave overtopping and sand overwash rate for each run.

The test series of the high dune geometry included one bare and two vegetation configurations. The narrow vegetation did not reduce the wave overtopping and sand overwash rate. On the contrary to the negligible effect of the narrow vegetation on dune evolution, the wide vegetation reduced foredune scarping, prevented wave overtopping initially, and reduced the overtopping and overwash rates after the initiation of wave overtopping. Hence, it can be concluded that the narrow vegetation did not enhance the dune resilience against destruction by wave-induced overwash. That is why the low dune was tested under bare and wide vegetation conditions only. These two tests examined the vegetation effects in the absence of foredune scarping which was observed during the high dune test series. The wide vegetation caused a reduction of dune erosion because the vegetation retarded wave uprush on the upward slope in the swash and inner surf zones and reduced the wave overtopping and overwash rates. Observations during the high and low test series indicated that the vegetation might have increased the sand mobilization in the vegetation zone.

The results of this investigation may be useful in designing a vegetation zone to reduce dune overwash. However, this study was limited to the specific diameter, height, spacing, alignment, and burial depth of rigid wooden dowels. It has to be noted that the chosen simulation of vegetation may not represent roots, trunks, branches, and leaves adequately. Furthermore, the factors of destruction by the wave force or vegetation uprooted due to erosion in the field were not considered in this study. In addition to experimental studies with different configurations, a large-scale experiment is required to quantify scale effects in the present small-scale experiment. Additional tests for low dunes without scarping in the absence of the vertical wall are necessary to gain results that are not influenced by the vertical wall once it is exposed. Nevertheless, the present experimental results will be useful for the initial development of a numerical model for vegetated dune overwash.

\section{ACKNOWLEDGMENTS}

This study was supported partly by the EU THESUS Project and the Army Corps of Engineers Coastal and Hydraulic Laboratory under Contract No. W912HZ-11-P-0173.

\section{REFERENCES}

Crowell, M., Coulton, K., Johnson, C., Westcott, J., Bellomo, D., Edelman, S., and E. Hirsch. 2010. An estimate of the U.S. population living in 100-year coastal flood hazard areas, Journal of Coastal Research, 26(2), 201-211.

Figlus, J., Kobayashi, N., Gralher, C., and V. Iranzo. 2011. Wave overtopping and overwash of dunes, Journal of Waterway, Port, Coastal, and Ocean Engineering, 137(1), 26-33.

Gutierrez, B.T., Williams, S.J., and E.R. Thieler. 2007. Potential for shoreline changes due to sea-level rise along the U.S. Mid-Atlantic Region, Open-File Report 2007-1278, U.S. Geological Survey.

United Nations Atlas of the Oceans. 2012. Human Settlements on the Coast. Available from http://www.oceansatlas.org/id/1877 (Accessed May 2012). 